\title{
BIOACCESSIBILITY PERFORMANCE DATA FOR FIFTY-SEVEN ELEMENTS IN GUIDANCE MATERIAL BGS 102
}

Elliott M. Hamilton ${ }^{a}$, Thomas S. Barlow ${ }^{a}$, Charles J.B. Gowing ${ }^{a}$, Michael J. Watts ${ }^{a^{*}}$

Inorganic Geochemistry, Centre for Environmental Geochemistry, British Geological Survey, Keyworth, Nottingham, NG12 5GG, UK

${ }^{*}$ Corresponding author

Keywords: bioaccessibility, unified bioaccessibility method, performance data, repeatability

\begin{abstract}
BGS 102, a guidance material for bioaccessible arsenic ( $\mathrm{As}$ ) and lead (Pb), was produced during validation of the in vitro Unified Bioaccessibility Method (UBM). This paper reports a compilation of reproducible bioaccessible guidance values for fifty-five additional elements in BGS 102, providing guidance for analysts to broaden the scope of UBM analyses for a wider range of elements based on data collected over an average of 60 separate analytical batches per element. Data are presented in categories for both gastric (STOM) and gastrointestinal (STOM+INT) extraction phases, where reproducibility, measured as relative standard deviation (RSD) was; $\leq 10 \%$ RSD for 27 elements (Mg, Al, Si, P, Ca, Cr, Mn, Co, $\mathrm{Ni}, \mathrm{As}, \mathrm{Rb}, \mathrm{Sr}, \mathrm{Y}, \mathrm{Ba}$, La, Ce, Pr, Nd, Sm, Eu, Tb, Gd, Dy, Ho, Er, Tm, Yb); between 10-20\% RSD for 10 elements (Li, K, V, Fe, Cu, Zn, Cd, Lu, Pb, U); and $\geq 20 \%$ RSD for 19 elements in the gastric phase (Be, B, S, Ti, Ga, Se, Zr, Nb, Mo, Ag, Sn, Sb, Cs, Hf, Ta, W, TI, Bi, Th). Two elements (Mg, Rb) met the $\leq 10 \%$ RSD criteria in the UBM gastrointestinal extraction phase due to the alkaline conditions of this phase precipitating out the majority of determinands. Certain elements, including $\mathrm{Na}, \mathrm{K}, \mathrm{Zn}$ and Se, were found to be a significant component of the extraction fluids with proportionally higher concentrations compared to the guidance material. Bioaccessible fractions (\%BAF) were also calculated, but were found to be a less reproducible format for confirming the accuracy of measurements. The low concentration of some elements of interest in BGS 102, such as antimony (Sb), justifies the preparation of an alternative certified reference material (CRM). This paper presents an opportunity to broaden the scope of the UBM method to address food security issues (e.g. $\mathrm{Fe}$ and $\mathrm{Zn}$ micronutrient deficiencies) and contributions to dietary intake from extraneous dust or soil through evidence of the analytical possibilities and current limitations requiring further investigation.
\end{abstract}




\section{Introduction}

The in vitro Unified Bioaccessibility Method (UBM) is the result of extensive work carried out by the Bioaccessibility Research Group of Europe (BARGE) to develop a validated method for the assessment of the human health risk associated with ingestion and subsequent gastro-intestinal digestion of contaminated soils. ${ }^{1}$ The total concentration of a metal present in a sample is not an effective measure of the mass that an organism can absorb through digestion; as a result there is a need to identify a bioaccessible proportion that has the potential to affect an organism. ${ }^{2}$ Bioaccessibility testing is commonly used as a substitute for bioavailability testing due to decreased costs, quicker turnaround and suitability in a commercial context. ${ }^{3}$

Due to the lack of reference materials with certified bioaccessible concentrations/fractions, a number of soil reference materials have been used as controls for in vitro studies. ${ }^{4}$ NIST 2710a (Montana Soil) or 2711a (Montana Soil II) are the most widely used ${ }^{5}$, but their bioaccessible fractions (\%BAF) are limited to a small number of elements such as arsenic (As) and lead $(\mathrm{Pb})$, and are only intended as reference values to confirm the accuracy of a bioaccessiblity procedure. As part of the UBM validation procedure a method-specific guidance material, BGS 102, was prepared at the British Geological Survey (BGS). ${ }^{6}$ Through inter-laboratory testing a guidance value was determined for As in both gastric and gastrointestinal extraction phases and for $\mathrm{Pb}$ in the gastric phase. However, many sitespecific contaminated land risk assessments require the analysis of additional elements to fully evaluate the potential risk to human health. ${ }^{7}$

The aim of this study is to assess the performance data of long-term analyses of BGS 102 to establish bioaccessible reference values for elements outside of the material's certification, creating a framework for future inter-laboratory comparison. The expansion of the range of elements beyond those on BGS 102's certificate to include elements that are typically used in contaminated land risk assessment would ensure a more comprehensive soil evaluation, and could increase the applicability of the UBM method to inform further research areas such as food security and micro-nutrient deficiency $y^{8,9,10,11,12,13}$, as well as assessment of exposure routes for other potentially harmful elements (PHEs). ${ }^{14,15}$

Micronutrient deficiencies (MNDs) can provoke the onset of physiological disorders, such as thyroid dysfunction (iodine deficiency) $)^{16}$, anaemia (Fe deficiency) ${ }^{17}$ and disruption of enzymatic and metabolic processes ( $\mathrm{n}$ deficiency). ${ }^{13}$ Micronutrient deficiencies are more prevalent in developing countries due to predominantly plant-based diets, with low transfer of 
micronutrients into crops resulting in insufficient concentrations to fulfil an individual's daily intake requirements. ${ }^{18}$ The impact of MNDs on a population is most commonly assessed using dietary surveys ${ }^{19}$, but this approach can be unreliable if inaccurate consumption data are reported by participants. ${ }^{20}$ In addition, these surveys cannot account for extraneous sources of micronutrients (e.g. soil dust contamination), which can have a significant, but ultimately undesired, contribution towards overall dietary intake. ${ }^{18}$ Bioaccessibility testing could be used to discriminate between intrinsic (e.g. plant-based) and extrinsic (e.g. soilbased) micronutrient sources, leading to better estimation of dietary intake. The change in extrinsic bioaccessibility due to modification of agricultural practices (biofortification, $\mathrm{pH}$ adjustment) could also be evaluated, resulting in more comprehensive dietary intake information and potentially greater control over exposure to extrinsic sources of micronutrients. ${ }^{21}$

The release of PHEs into the environment through mining activity is well documented. ${ }^{22,23}$ The use of biomarkers can be beneficial when comparing exposure within populations. ${ }^{24}$ Biomarkers can only indicate short or long-term exposure to $\mathrm{PHEs}^{25}$, and so additional diagnostic procedures are required to identify routes of exposure. Bioaccessibility testing could be used to indicate PHE adsorption from a number of pathways, including geophagy practices ${ }^{26}$ and ingestion of extraneous dust through hand-to-mouth contact. ${ }^{27}$ It could also reinforce soil screening studies discriminating between lithogenic and anthropogenic sources of metals. ${ }^{28}$ Additional guidance values for BGS 102 would increase the number of elements that could be reliably investigated, therefore expanding the scope of existing research and/or producing verifiable data for future examination.

\section{Materials and Methods}

\subsection{Reagents}

All reagents used were of analytical grade. UBM extraction solutions were prepared according to instructions in the BARGE protocol using deionised water $(18.2 \mathrm{M} \Omega \mathrm{cm}$; Millipore, UK). ${ }^{29}$ Multi-element calibration standards were prepared on the morning of each analytical run from $10 \mathrm{mg} \mathrm{I}^{-1}$ stock solutions (SPEX Certiprep, Middlesex, UK) using $1 \% \mathrm{v} / \mathrm{v}$ nitric $\left(\mathrm{HNO}_{3}\right)$ and $0.5 \% \mathrm{v} / \mathrm{v}$ hydrochloric acid $(\mathrm{HCl})$ (Romil, Cambridge, UK). Major elements ( $\mathrm{Al}, \mathrm{Fe}, \mathrm{Mg}, \mathrm{Ca}, \mathrm{Na}, \mathrm{K}, \mathrm{Ti}, \mathrm{Mn}, \mathrm{Sr}, \mathrm{Ba}, \mathrm{Zr}$ ) were calibrated using in-house standards prepared from 10,000 $\mathrm{mg} \mathrm{l}^{-1}$ mono-elemental stock solutions (Romil, Cambridge, UK).

The ICP-MS was optimised before each analytical run using a $5 \mu \mathrm{g} \mathrm{I}^{-1}$ tuning solution consisting of $\mathrm{Li}, \mathrm{Ce}, \mathrm{Y}$ and $\mathrm{TI}$ (SPEX CertiPrep, USA). An internal standard solution 
consisting of Sc, Ge, Rh, In, Te and Irwas added to each sample in a 1:10 ratio via a Tpiece to correct for signal drift. Sc was obtained from Sigma-Aldrich (Gillingham, Dorset, UK); Ge, Rh, In and Ir were obtained from SPEX Certiprep (Middlesex, UK); and Te was obtained from SCP Science (Montreal, Canada). The internal standard stock solutions were diluted with $1 \% \mathrm{v} / \mathrm{v} \mathrm{HNO}_{3}, 0.5 \% \mathrm{HCl}$ to achieve an individual count rate between 100,000 and 500,000 counts per second (CPS), which was monitored before the start of each analytical run.

\subsection{Instrumentation}

Analysis of 57 elements was carried out using an Agilent $7500 \mathrm{cx}$ ICP-MS fitted with a CETAC ASX-520 autosampler. Sample introduction from the autosampler to the ICP-MS was controlled by a CETAC ASXpress+ vacuum pump. Multi-element quality control (QC) check standards, containing the trace elements of interest at $25 \mathrm{\mu g} \mathrm{I}^{-1}$, and a separate major element QC were analysed at the start and end of each run and after no more than every 20 samples. To overcome polyatomic interferences the ICP-MS collision cell was operated in He mode at a flow rate of $5.5 \mathrm{ml} \mathrm{min}^{-1}$ for all analytes except $\mathrm{Se}$, for which $\mathrm{H}_{2}$ gas was used at $4.5 \mathrm{ml} \mathrm{min}^{-1}$ due to the more intense interferences experienced with $\mathrm{Se}$ as a result of argon (Ar) dimers formed in the plasma. ${ }^{30}$ Samples were diluted 100 -fold with $1 \% \mathrm{v} / \mathrm{v} \mathrm{HNO}_{3}$. $0.5 \% \mathrm{v} / \mathrm{v} \mathrm{HCl}$ before analysis. This has the additional benefit of reducing the potential for precipitation of $\mathrm{Sn}$ and $\mathrm{Ag}$ from solution. Quantitative data analysis was carried out using MassHunter Workstation software (Agilent).

\subsection{Analytical Performance of 57 Elements}

The large amount of elemental data acquired for each run required verification to demonstrate the quality of the ICP-MS analysis. The accuracy of each analytical run was confirmed using three separate in-house quality control (QC) solutions prepared from purchased stock solutions, diluted to an intermediate concentration of $1 \mathrm{mg} \mathrm{L}^{-1}$ and analysed after no more than twenty samples; "QCA3" included $\mathrm{Li}, \mathrm{Be}, \mathrm{V}, \mathrm{Cr}, \mathrm{Mn}, \mathrm{Co}, \mathrm{Ni}, \mathrm{Cu}, \mathrm{Zn}, \mathrm{As}$, $\mathrm{Se}, \mathrm{Sr}$, Mo, Ag, Cd, Sb, Ba, Tl, Pb and U at $25 \mu \mathrm{L} \mathrm{L}^{-1}$, "QCBC" included Ti, Rb, Y, Zr, Nb, Sn, Cs, La, Ce, Pr, Nd, Sm, Eu, Tb, Gd, Dy, Ho, Er, Tm, Yb, Lu, Hf, Ta, W and Th at $25 \mu \mathrm{g} \mathrm{L}^{-1}$ and "QCMaj" included $\mathrm{Na}, \mathrm{Mg}, \mathrm{Al}, \mathrm{S}, \mathrm{K}, \mathrm{Ca}$ and $\mathrm{Fe}$ at $40 \mathrm{mg} \mathrm{L}^{-1}$; $\mathrm{Ti}$ and $\mathrm{Mn}$ at $4000 \mathrm{mg} \mathrm{L}^{-1}$; $\mathrm{Sr}, \mathrm{Zr}$ and $\mathrm{Ba}$ at $800 \mathrm{mg} \mathrm{L}^{-1}$; and $\mathrm{P}$ at $8 \mathrm{mg} \mathrm{L}^{-1}$. To assess the performance of each element, the average concentrations for each $Q C$ within the UBM analytical runs were calculated and used to determine percentage bias by subtracting the average from the target value (Figures $1,2$ and 3$)$. 


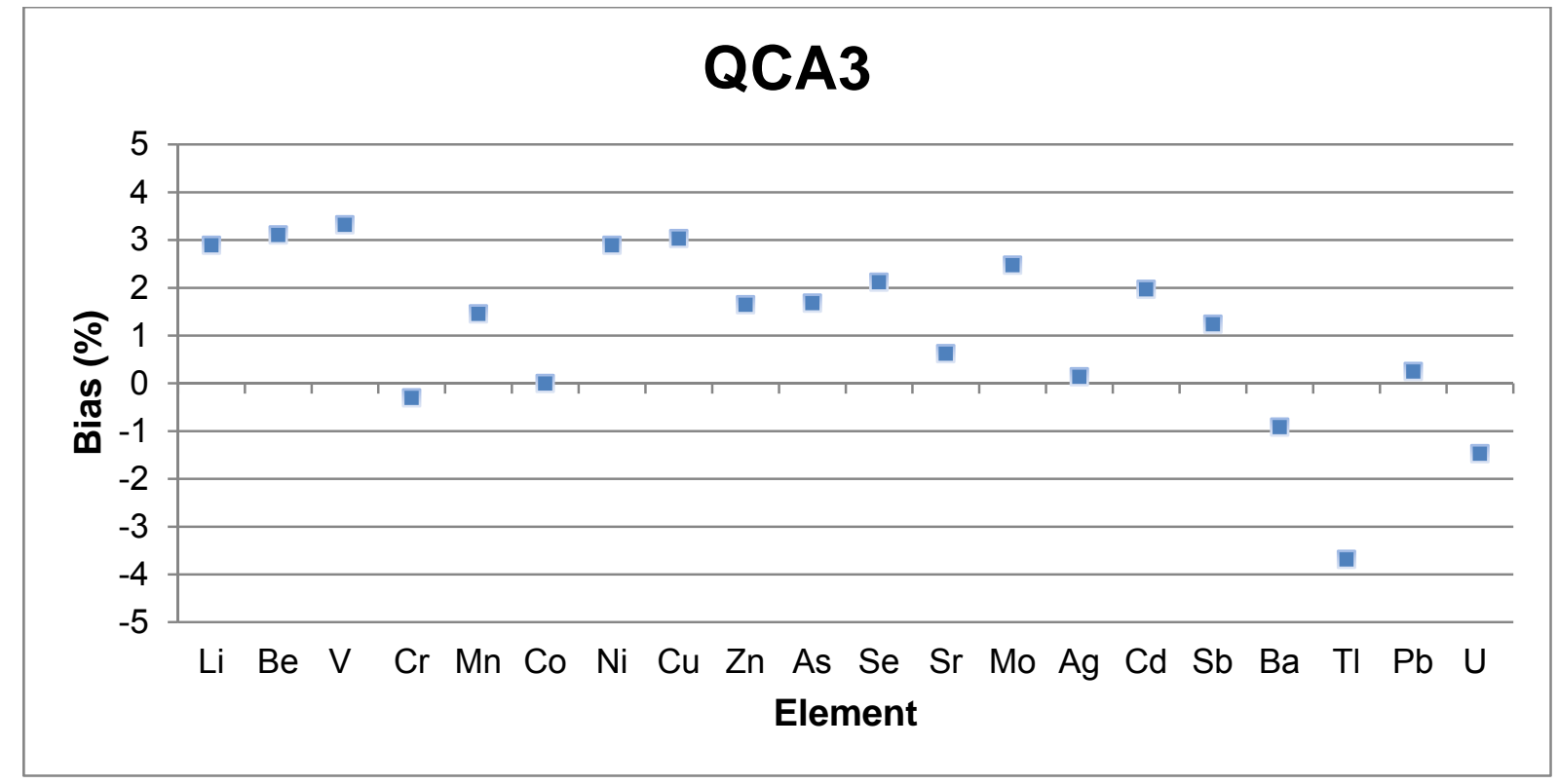

Figure 1: Percentage bias for QCA3 elements over the duration of the study

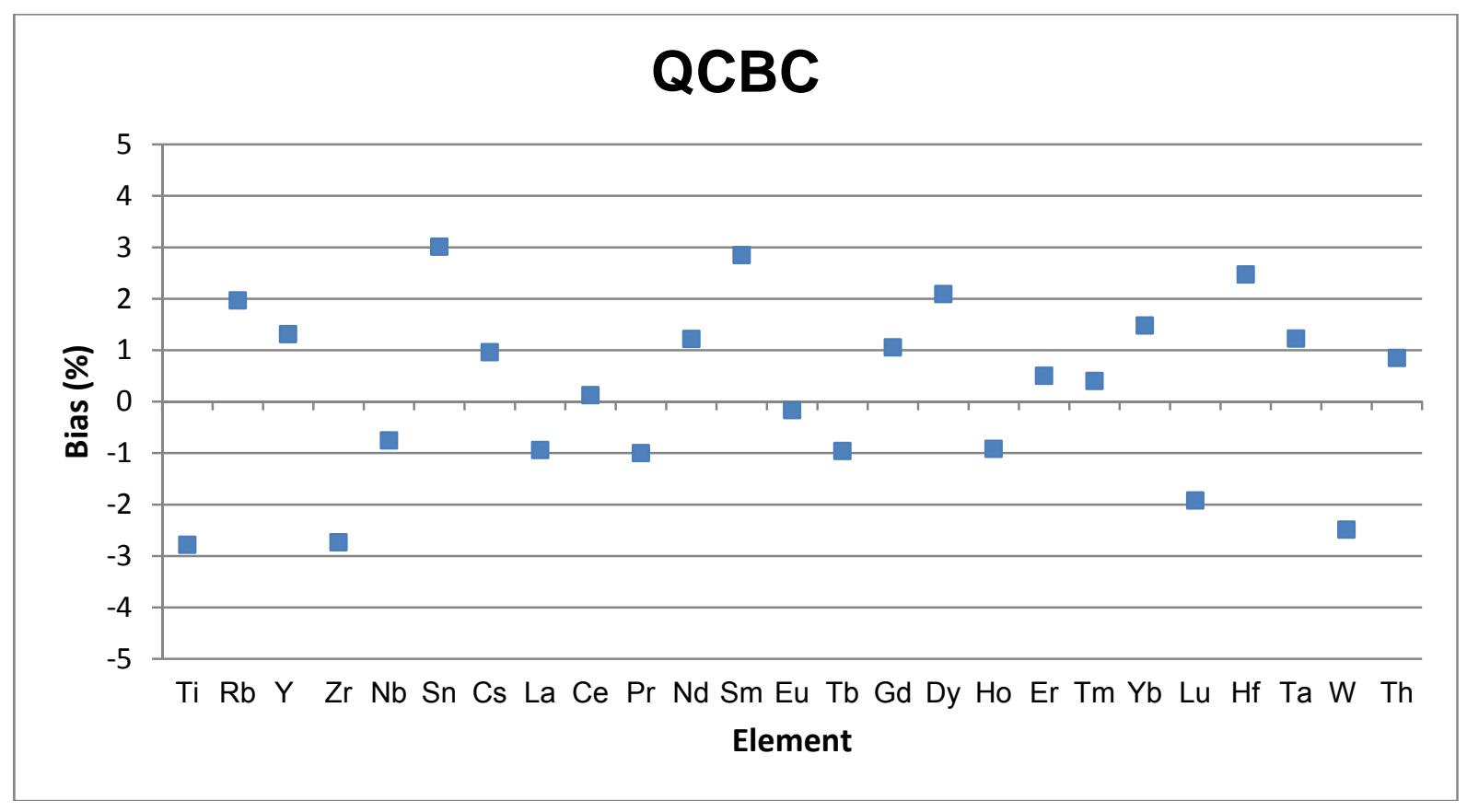

Figure 2: Percentage bias for QCBC elements over the duration of the study 


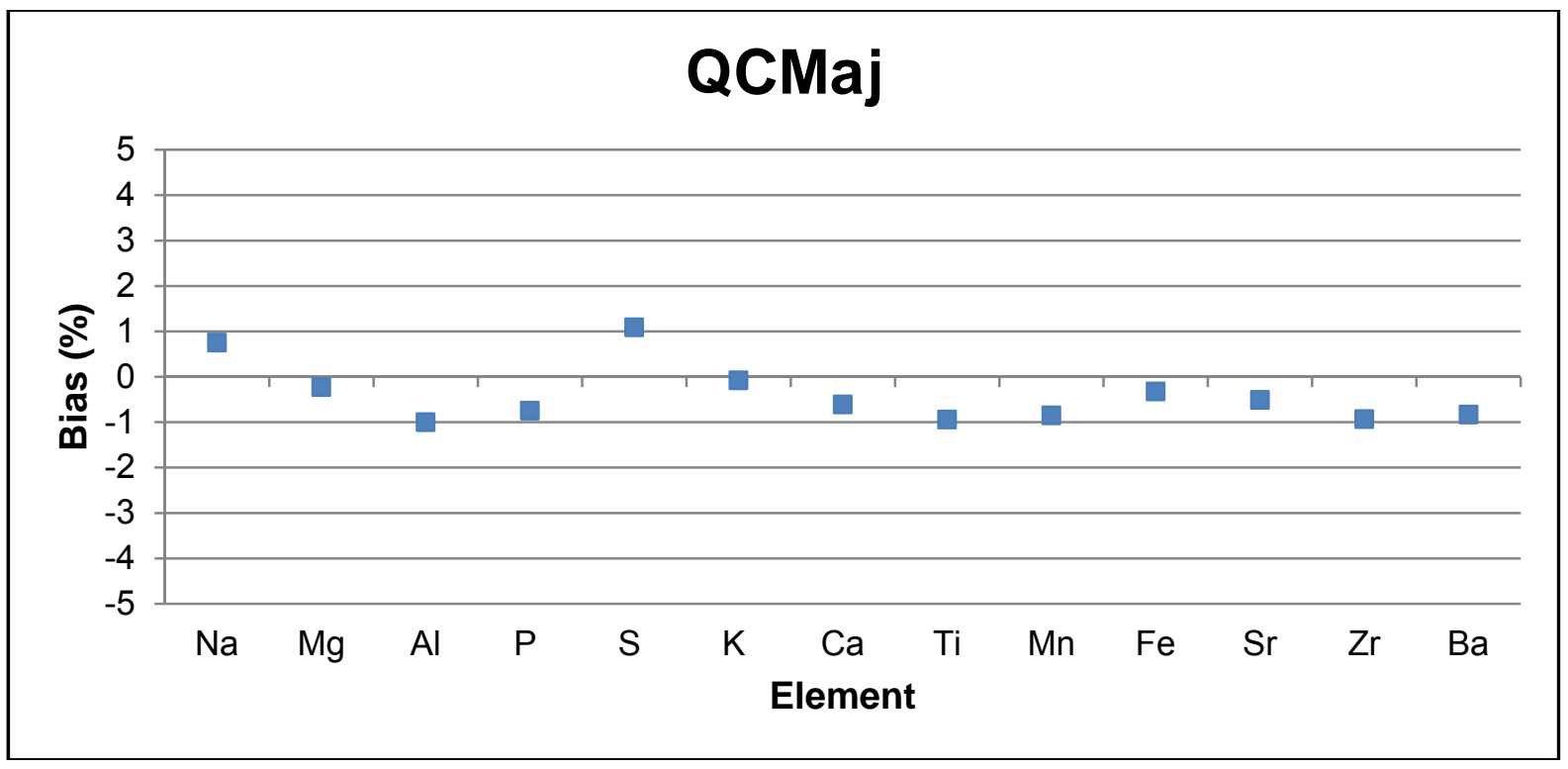

Figure 3: Percentage bias for QCMaj elements over the duration of the study

Over the duration of the study, every element displayed QC data within $+/-5 \%$ bias for QCA3 (Fig. 1) and QCBC (Fig. 2) and within +/- 2\% for QCMaj (Fig. 3), indicating acceptable analytical performance and increased confidence in the data produced for the unknown samples. The accuracy for the method-specific guidance material BGS 102 on the certified elements $\mathrm{As}$ and $\mathrm{Pb}$ acted as a secondary confirmation of the analysis quality (see section 3.1).

Each analytical run utilised the ICP-MS' collision cell to remove common spectral interferences. Despite this, the analysis of solid dissolutions can still be prone to interferences on the larger-mass elements due to their higher concentrations in geological materials and contaminated land samples. ${ }^{30}$ These typically manifest themselves as oxides and doubly-charged interferences, which have the potential to create false-positive signals on other elements. To overcome these, Ce, $\mathrm{Nd}, \mathrm{Sm}, \mathrm{Gd}$ and $\mathrm{Dy}$ standards at $100 \mu \mathrm{g} \mathrm{L}^{-1}$ were analysed at the start of each run to induce interferences on the elements (e.g. ${ }^{150} \mathrm{Nd}^{++}$ and ${ }^{150} \mathrm{Sm}^{++}$on ${ }^{75} \mathrm{As}$ ), with a correction factor calculated during data workup used to remove the interference contribution to the unknown data. The common oxide interference ${ }^{137} \mathrm{Ba}^{16} \mathrm{O}^{+}$ on ${ }^{153} \mathrm{Eu}$ was corrected using a Ba standard at $1000 \mu \mathrm{g} \mathrm{L}^{-1}$ due to the lower abundance of ${ }^{137} \mathrm{Ba}$.

\subsection{UBM extractions of BGS 102}

The standard methodology for the UBM procedure is outlined by BARGE and was used for all extractions. ${ }^{31}$ To confirm the accuracy of the extraction procedure, BGS 102 was 
extracted once with every UBM phase batch $(n=10$, one procedural blank, seven unknowns, one duplicate of the unknowns, one guidance material). The data were produced over approximately five years of UBM extractions. Mixed-acid digestion of BGS 102 was also undertaken with each batch to measure total elemental concentrations. ${ }^{32}$

Simulated digestive fluids, representing saliva, gastric, duodenal and bile, were produced from inorganic and organic reagents and used to replicate the three main compartments of the human gastro-intestinal tract involved in digestion: mouth, stomach and small intestine. $0.6 \pm 0.01 \mathrm{~g}$ of BGS 102 was accurately weighed in duplicate into $85 \mathrm{ml}$ Nalgene ${ }^{\circledR}$ oak ridge tubes (Thermo Scientific, UK). Simulated saliva and gastric fluid was added to each tube, the $\mathrm{pH}$ was adjusted to $1.2 \pm 0.05$, followed by one hour of end-over-end agitation in a temperature-controlled water bath held at $37^{\circ} \mathrm{C}$. One of the duplicates was extracted through centrifugation at $4500 \mathrm{~g}$ for 15 minutes (STOM phase), whilst the second was taken through the stomach+intestine extraction using simulated duodenal and bile fluids $(\mathrm{pH}$ adjusted to $6.3 \pm 0.5$ where necessary to account for natural buffering of the sample material).

The stomach+intestine extraction (STOM+INT phase) involved four hours of end-over-end agitation $37^{\circ} \mathrm{C}$, followed by an identical centrifugation procedure. For both extractions, $10 \mathrm{ml}$ of the supernatant was collected and preserved with $0.2 \mathrm{ml}$ concentrated (15.9 M) $\mathrm{HNO}_{3}$ prior to analysis by ICP-MS. Data from an average of 60 separate extraction runs per element have been collated in this exercise, although not all of these were for the full number of elements evaluated in this study. This accounts for the discrepancy between the number of extractions for each phase, which could be misconstrued as manipulation of the data in order to obtain optimum summary statistics.

\section{Results and Discussion}

\subsection{Repeatability of UBM measurements for certified elements (As, $P b)$}

BGS 102 is certified for $\mathrm{As}$ and $\mathrm{Pb}$, therefore both the accuracy and precision of the extraction procedure and analysis can be verified through comparison of the data with the certified values. Demonstrating acceptable accuracy and precision for extractions of BGS 102 is necessary to increase confidence in the additional elemental reference values produced (Figures 4 and 5). Precision was expressed as the percentage relative standard deviation (\%RSD).

Arsenic displayed $<10 \%$ RSD in the STOM phase over 89 separate measurements, indicating good repeatability. The box and whisker plot for As in the STOM phase shows a 
small distribution of data with an average As concentration of $3.9 \pm 0.4 \mathrm{mg} \mathrm{kg}^{-1}$. A wider spread in the data can be observed for $\mathrm{Pb}$ in the STOM phase $(\mathrm{n}=75)$, with an average concentration of $15.3 \pm 3.0 \mathrm{mg} \mathrm{kg}^{-1}$. The potential for $\mathrm{Pb}$ contamination resulting from carryover of high sample concentrations could explain the larger data distribution, particularly as $\mathrm{Pb}$ is more mobile in the acidic conditions of the STOM phase. ${ }^{33}$

The STOM+INT phase showed a marginally wider distribution for As $(n=77)$ over a similar number of measurements $\left(3.3 \pm 0.4 \mathrm{mg} \mathrm{kg}^{-1}\right)$, indicating no significant difference in the behaviour of As between the two extraction phases. This observation has been noted in a number of studies and is most likely due to the tendency of As to form anionic species in solution, decreasing the influence of $\mathrm{pH}$ on the metal's mobility in solution. ${ }^{34,35}$ In comparison, $\mathrm{Pb}(\mathrm{n}=56)$ showed a marked decrease in the measured bioaccessible concentrations due to its lower solubility at the higher $\mathrm{pH}$ of the STOM+INT phase.

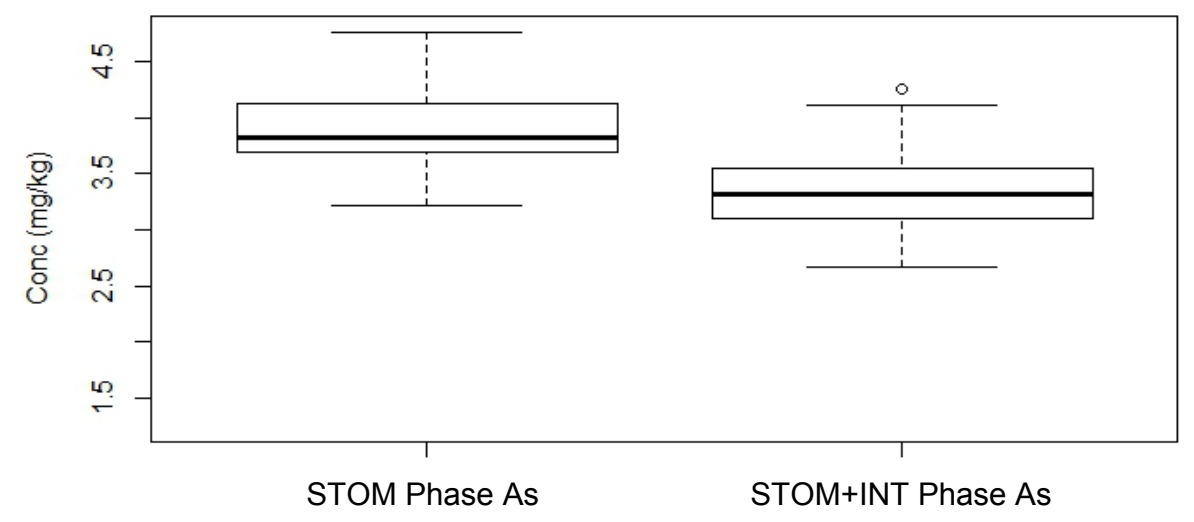

Figure 4: Box and whisker plot summarising bioaccessible concentrations of As in STOM ( $\mathrm{n}$ $=89)$ and STOM+INT $(n=77)$ phases

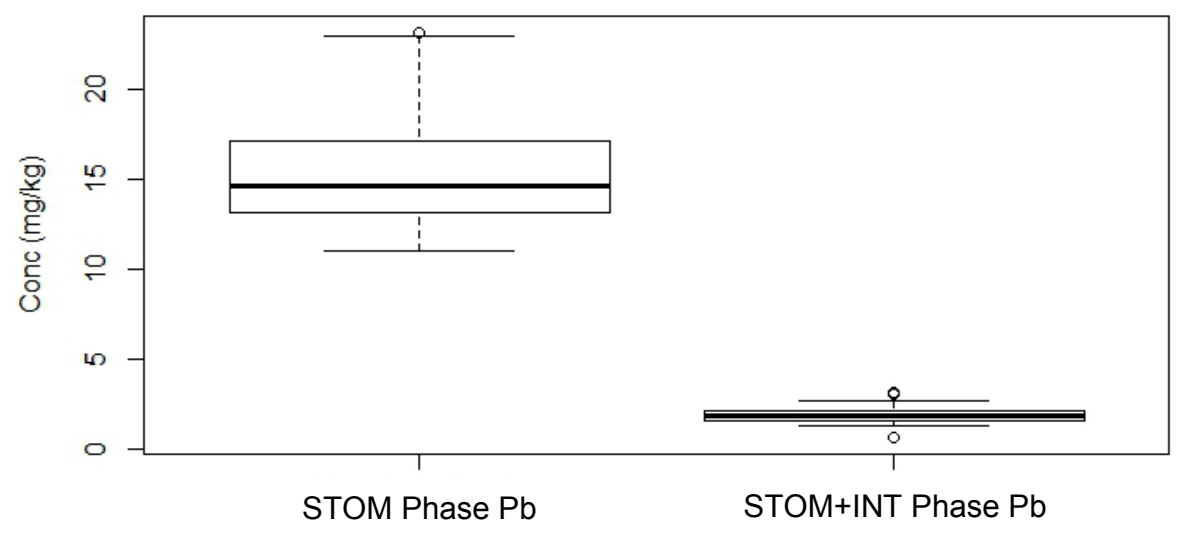

Figure 5: Box and whisker plot summarising bioaccessible concentrations of $\mathrm{Pb}$ in STOM ( $\mathrm{n}$ $=75)$ and STOM+INT $(n=56)$ phases 
The compiled concentrations (Table 1 and 2) and uncertainties show good agreement with the certified values for As and $\mathrm{Pb}$ in BGS $102,{ }^{6}$ demonstrating proficiency and validating the method used in determining values for uncertified elements. The certificate for BGS 102 reports bioaccessible element concentrations of $5.4 \pm 2.4 \mathrm{mg} \mathrm{kg}^{-1}$ for As and $13 \pm 6 \mathrm{mg} \mathrm{kg}^{-1}$ for $\mathrm{Pb}$, giving accuracies of $72 \%$ and $118 \%$ respectively from the averages reported in this paper. However, because the uncertainties reported in this paper indicate a much tighter distribution of values compared to the guidance values (both calculated at one standard deviation from the mean), the seemingly poor accuracies become less significant and the error can be attributed to the larger spread of data used to calculate the certified bioaccessible concentrations. In addition, the certificate data may not have been corrected for the doubly charged interferences from ${ }^{150} \mathrm{Nd}^{++}$and ${ }^{150} \mathrm{Sm}^{++}$, both of which can give falsepositive results on ${ }^{75} \mathrm{As}$.

\subsection{Reference values for uncertified elements $(n=55)$}

At the time of writing, uncertified BGS 102 elemental concentrations have not been widely reported in the literature for comparison. Tokatlıoğlu et al. reported five reference values as part of a study into nutritional supplements ${ }^{11}$ whilst Boisa et al. reported three for their work assessing the bioaccessibility of PHEs in metallurgical waste ${ }^{36}$. In both studies, the UBM method was modified for $0.3 \mathrm{~g}$ soil as opposed to the $0.6 \mathrm{~g}$ specified in the UBM protocol. ${ }^{29}$ As is the case with this study, none of the reference values were validated using in vivo techniques. This study provides the first reference dataset for a wider range of elements in a guidance material specific to the UBM method.

The mean concentrations for uncertified elements in both STOM and STOM+INT phases are reported in Tables 1 and 2 respectively.

\subsubsection{STOM Phase}

Twenty-seven elements, including As, displayed $\leq 10 \% \mathrm{RSD}$, demonstrating good repeatability over the evaluated measurements. A number of these can be highlighted as elements of interest to commercial and industrial sectors, particularly for contaminated land risk assessment and environmental consultancy groups. ${ }^{37}$ A further ten elements showed acceptable repeatability $(10-20 \% \mathrm{RSD})$. Nineteen elements did not meet the repeatability criteria set for this study as the observed concentrations were close to or below the instrumental detection limit, increasing the significance of instrumental noise on the calculated precision. Bioaccessibility testing of these elements would require preparation of additional reference materials or a suite of reference materials. 
Sodium ( $\mathrm{Na}$ ), potassium $(\mathrm{K})$ and calcium $(\mathrm{Ca})$ demonstrated good performance data but are also present at consistently high concentrations in STOM phase blanks. These common procedural components can be attributed to the salts used in the preparation of the UBM reagents; as a result their presence in BGS 102 extractions will be due to the fluids and do not reflect the bioaccessible fraction of the element for the guidance material; therefore, $\mathrm{Na}$ has been omitted from the list of elements with acceptable performance data (see section 3.4).

\subsubsection{STOM+INT Phase}

Owing to the higher $\mathrm{pH}$ of the STOM+INT extraction phase only four elements demonstrated acceptable reproducibility ( $<10 \% \mathrm{RSD})$. Arsenic was marginally outside of these criteria at $12 \%$ RSD over 77 measurements. Arsenic exists as anionic species in solution, therefore $\mathrm{pH}$ does not have a significant impact on its mobility. ${ }^{35}$ When an element is noticeably affected by the extraction phase $\mathrm{pH}$ but demonstrates repeatability in the STOM phase, the STOM phase data is used as a more conservative estimate of bioaccessibility. ${ }^{38}$ Similar to the STOM phase, $\mathrm{Na}$ and $\mathrm{K}$ demonstrated good performance data but are present in the UBM procedural blanks, indicating a significant contribution from the reagents.

\subsection{Bioaccessible Fractions (\%BAF) of Elements in BGS 102}

In addition to phase-specific bioaccessible reference values, the percentage bioaccessible fractions (\%BAF) was also calculated and assessed for each element across forty separate analytical batches where both mixed acid digestion and bioaccessibility data were available (Table 3). Results from UBM bioaccessibility tests are most commonly, but not always, expressed as \%BAF, calculated as:

$$
\operatorname{BAF}(\%)=\left(\frac{\text { Element }_{\text {bioaccessible }}}{\text { Element }_{\text {total }}}\right) \times 100
$$

where Element $_{\text {bioaccessible is the comparatively higher bioaccessibility concentration obtained }}$ from either the STOM or STOM+INT phase.

Twelve elements met the study repeatability criteria of $\leq 10 \%$ RSD. The \%BAF could not be calculated for boron (B) and silicon (Si) due to decomposition and volatilisation during the mixed acid digestion procedure ${ }^{32}$. Arsenic was marginally outside of the acceptance criteria with $11 \% \mathrm{RSD}$, whilst Pb performed poorly with $32 \% \mathrm{RSD}$. Certain elements performed poorly due to inherently low bioaccessiblity values. ${ }^{31}$ Using the \%BAF is efficient for data 
presentation, but as the summary statistics suggest bioaccessible concentrations are a more reproducible way of confirming the accuracy of UBM extraction data for a larger number of elements.

\subsection{Influence of reagents on performance data}

Twenty-four inorganic and organic reagents are used to prepare the extraction fluids for the UBM method, leading to significant reagent concentrations that will bias the performance data for particular elements as the primary component of the measured concentration will be from the extraction fluids as opposed to BGS 102. The high concentrations for $\mathrm{Na}, \mathrm{K}$ and $\mathrm{Ca}$ are immediately apparent as they are present in many of the inorganic salts used $(\mathrm{NaCl}$, $\mathrm{KCl}, \mathrm{CaCl}_{2}$ ), but a more comprehensive assessment of the UBM blanks was performed to establish additional elements with significant concentrations (Table 4).

Table 4: Mean concentrations $\left(\mathrm{mg} \mathrm{l}^{-1}\right)$ of procedural contaminants in UBM blanks $(n=30)$

\begin{tabular}{|c|c|c|c|c|c|c|c|c|}
\hline & $\mathrm{Na}$ & Mg & $\mathbf{K}$ & Ca & $\mathbf{C u}$ & $\mathbf{Z n}$ & Se & $\mathbf{R b}$ \\
\hline Phase & $\mathrm{mg} \mathrm{l}^{-1}$ & $\mathrm{mg} \mathrm{l}^{-1}$ & $\mathrm{mg} \mathrm{I}^{-1}$ & $\mathrm{mg} \mathrm{l}^{-1}$ & $\mathrm{mg} \mathrm{I}^{-1}$ & $\mathrm{mg} \mathrm{l}^{-1}$ & $\mathrm{mg} \mathrm{l}^{-1}$ & $\mathrm{mg} \mathrm{I}^{-1}$ \\
\hline STOM & 870 & 2 & 510 & 52 & 0.03 & 0.14 & 0.003 & 0.03 \\
\hline STOM+INT & 2815 & 6 & 399 & 51 & 0.02 & 0.13 & 0.002 & 0.02 \\
\hline $\begin{array}{c}\text { Contribution to BGS } 102 \\
\text { average STOM (\%) } \\
\end{array}$ & 100 & 14 & 100 & 10 & 15 & 14 & 86 & 40 \\
\hline $\begin{array}{c}\text { Contribution to BGS } 102 \\
\text { average STOM+INT (\%) }\end{array}$ & 100 & 53 & 100 & 23 & 26 & 100 & 100 & 50 \\
\hline
\end{tabular}

note: contribution percentages calculated from solution data $\left(\mathrm{mg} \mathrm{l}^{-1}\right)$, not solid data $\left(\mathrm{mg} \mathrm{kg}^{-1}\right)$

The mean concentrations calculated for $\mathrm{Na}$ and $\mathrm{K}$ in BGS 102 are solely due to the reagents, rather than $\mathrm{Na}$ and $\mathrm{K}$ present in the guidance material. The precipitation of elements from the STOM+INT phase is the likely explanation for the greater influence of reagents for this phase, as they are proportionally greater compared to the CRM concentrations. If the validation of UBM bioaccessibility data for $\mathrm{Cu}, \mathrm{Zn}$ and $\mathrm{Rb}$ is required then higher-purity reagents should be used to prepare extraction fluids. Despite its poor performance (>20\% RSD), Se has been included to highlight the significance of the reagent contamination on trace element data. Further work is required to establish whether the measured $\mathrm{Se}$ is in fact an interference caused by the extraction fluids' behaviour in the $\mathrm{H}_{2}$ reaction mode of the ICP-MS. 
The bioaccessible concentrations for $\mathrm{Na}, \mathrm{K}, \mathrm{Zn}$ and Se have been retained in Tables 1+2 for completion only and have been omitted from the lists mentioned in the abstract and conclusion of this publication.

\section{Conclusions}

Through repeat UBM extractions and analyses of BGS 102, a framework of reproducible bioaccessibility guidance values have been established for 27 elements in the STOM phase (Mg, Al, Si, P, Ca, Cr, Mn, Co, Ni, As, Rb, Sr, Y, Ba, La, Ce, Pr, Nd, Sm, Eu, Tb, Gd, Dy, Ho, $\mathrm{Er}, \mathrm{Tm}, \mathrm{Yb})$ and two elements in the STOM+INT phase (Mg, Rb), displaying RSDs of $\leq 10 \%$ over an average of 60 separate measurements per element. Despite the significance of $\mathrm{Pb}$ to bioaccessibility studies, the STOM phase RSD was only just within the $10-20 \%$ category. This could be due to differences in $\mathrm{pH}$ control criteria between iterations of the UBM protocol, which has been shown to significantly affect repeatability. ${ }^{35}$ Within both phases seven elements that displayed promising performance data are also present at significant concentrations in the UBM extraction fluids, calling attention to the issue of purity when selecting reagents for preparation of synthetic digestive fluids. A number of these elements $(\mathrm{Na}, \mathrm{Mg}, \mathrm{K}, \mathrm{Ca}$ ) are inherent to the process, but $\mathrm{Cu}$ and $\mathrm{Zn}$ in particular have a contribution low enough to allow for purer reagents to remediate this issue.

Publication of data from a larger number of elements would allow augmentation of the UBM method with more studies. For example, assessment of intrinsic and extrinsic sources of $\mathrm{Fe}$ (e.g. dust on crops) and their respective bioaccessibilities could lead to better estimation of dietary intake. ${ }^{9}$ The consequences of rare earth and radioactive element disposal could be explored through bioaccessibility testing, particularly the issue of Th and $U$ contaminated slurry tailings and their environmental impact. ${ }^{39}$ This is an area of research that has been neglected by the bioaccessibility community, but could be used to estimate the committed dose, and therefore the radiation risk, associated with ingestion over different timeframes. ${ }^{40}$

With increased reagent purity, bioaccessibility testing of foodstuffs (rice, vegetation) could inform micronutrient deficiency (MND) research and the efficacy of biofortification, particularly in the case of $\mathrm{Zn} .^{8,13}$ Zinc plays an important role in a vast number of biological processes, therefore the verification of $\mathrm{Zn}$ bioaccessibility data could apprise a number of nutritional and lifestyle studies in addition to micronutrient deficiencies, including drug delivery systems and diabetes research. ${ }^{41,42}$ Bioaccessibility testing could be used to study the effects of modified farming techniques (liming, organic reincorporation) on metal transfer into crops, complimenting bioaccessibility data for the parent soil and allowing for speciation data to be incorporated where appropriate. For example, uptake of chromium $(\mathrm{Cr})$ into plants 
is highly dependent on its speciation, with hexavalent chromium $(\mathrm{Cr}(\mathrm{VI}))$ being more mobile in the environment than the trivalent form $(\mathrm{Cr}(\mathrm{III}))$. $\mathrm{Cr}(\mathrm{VI})$ is highly-toxic and a recognised carcinogen whilst $\mathrm{Cr}$ (III) plays a role in the metabolism of carbohydrate, fat and protein. ${ }^{43}$ Liming has been shown to reduce soil organic content ${ }^{44}$, which can in turn increase bioaccessibility of $\mathrm{Cr}(\mathrm{VI})$; the subsequent increase in soil $\mathrm{pH}$ through liming also decreases the likelihood of $\mathrm{Cr}(\mathrm{VI})$ reduction to the less toxic $\mathrm{Cr}(\mathrm{III}) .{ }^{45}$ Post-fortification bioaccessibility testing of soils and staple crops would be a fast, inexpensive technique that could be carried out on a routine basis to monitor fortification programmes and highlight any issues arising from changes in agricultural practices.

In addition to MND research, the health risk associated with the anthropogenic release of potentially harmful elements (PHEs) into the environment could also be assessed on a wider scale. For example, rare earth elements (REEs) have been used extensively in China as microelement fertilisers for crop growth and improved yield. ${ }^{46,47,48}$ The low mobility of REEs in the environment can lead to bioaccumulation in crops and soil, increasing concern about the ingestion pathway as an exposure route for REEs. ${ }^{49}$ There is no established biological role for REEs, but $\mathrm{La}^{3+}$ can compete with $\mathrm{Ca}^{2+}$ in biological systems ${ }^{50}$, causing disruption of digestive enzymes and poor adsorption of essential substrate constituents. ${ }^{51}$ Bioaccessibility testing could identify at-risk areas and compliment biomarker data (blood, nails, hair, urine) for the monitoring of REE-body burden, improving the biological understanding of REEs and what risk they pose to human health.

Further work includes a comprehensive inter-laboratory trial, allowing for outright certification of elements or additional verification of reference values obtained during this study. This will increase confidence in reported data and could expand the scope of the UBM method beyond land quality management and risk assessment to include environmental, agricultural and health studies. The low concentrations of some potentially harmful elements highlighted within the bioaccessibility community $(\mathrm{Be}, \mathrm{Se}, \mathrm{Sb}$ ) also require the preparation of an alternative CRM or suite of CRMs to broaden the scope of UBM bioaccessibility testing of contaminated land or agricultural soils.

\section{Acknowledgments}

This work is published with the permission of the Executive Director of the British Geological Survey. The authors would like to thank Dr Mark Cave (BGS) for his comments on the manuscript. 


\section{References}

(1) BARGE: The Bioaccessibility Research Group of Europe.

(2) Cave, M. R.; Wragg, J.; Palumbo, B.; Klinck, B. A. "Measurement of the Bioaccessibility of Arsenic in UK Soils," Environment Agency, 2002.

(3) Kelley, M. E.; Brauning, S. E.; Schoof, R. A.; Ruby, M. V.: Assessing oral bioavailability of metals in soil; Batelle Press: Columbus. OH, 2002.

(4) EPA: Standard Operating Procedure for an In Vitro Bioaccessibility Assay for Lead in Soil. In EPA 9200.2-86, April 2012.

(5) Koch, I.; Reimer, K.; Bakker, M.: Variability of bioaccessibility results using seventeen different methods on a standard reference material, NIST 2710. Journal of Environmental Science and Health, Part A: Toxic/Hazardous Substances and Environmental Engineering 2013, 48, 641-655.

(6) Wragg, J. "Certificate of Analysis: BGS Guidance Material 102 Ironstone Soil," 2009.

(7) Broadway, A.; Cave, M. R.; Wragg, J.; Fordyce, F. M.; Bewley, R. J. F.; Graham, M. C.; Ngwenya, B. T.; Farmer, J. G.: Determination of the bioaccessibility of chromium in Glasgow soil and the implications for human health risk assessment. Science of The Total Environment 2010, 409, 267277.

(8) Hurst, R.; Siyame, E. W. P.; Young, S. D.; Chilimba, A. D. C.; Joy, E. J. M.; Black, C. R.; Ander, E. L.; Watts, M. J.; Chilima, B.; Gondwe, J.; Kang'ombe, D.; Stein, A. J.; Fairweather-Tait, S. J.; Gibson, R. S.; Kalimbira, A. A.; Broadley, M. R.: Soil-type influences human selenium status and underlies widespread selenium deficiency risks in Malawi. Sci. Rep. 2013, 3.

(9) Joy, E. J. M.; Ander, E. L.; Young, S. D.; Black, C. R.; Watts, M. J.; Chilimba, A. D. C.; Chilima, B.; Siyame, E. W. P.; Kalimbira, A. A.; Hurst, R.; Fairweather-Tait, S. J.; Stein, A. J.; Gibson, R. S.; White, P. J.; Broadley, M. R.: Dietary mineral supplies in Africa. Physiologia Plantarum 2014, 151, 208-229.

(10) Fernández-García, E.; Carvajal-Lérida, I.; Pérez-Gálvez, A.: In vitro bioaccessibility assessment as a prediction tool of nutritional efficiency. Nutrition Research 2009, 29, 751-760.

(11) Tokalığlu, Ş.; Clough, R.; Foulkes, M.; Worsfold, P.: Bioaccessibility of $\mathrm{Cr}, \mathrm{Cu}, \mathrm{Fe}, \mathrm{Mg}$, $\mathrm{Mn}, \mathrm{Mo}$, Se and $\mathrm{Zn}$ from nutritional supplements by the unified BARGE method. Food Chemistry 2014, 150, 321-327.

(12) Khouzam, R. B.; Pohl, P.; Lobinski, R.: Bioaccessibility of essential elements from white cheese, bread, fruit and vegetables. Talanta 2011, 86, 425-428. 
(13) Ahmad, W.; Watts, M. J.; Imtiaz, M.; Ahmed, I.; Zia, M. H.: Zinc deficiency in soils, crops and humans: A Review. Agrochimica 2012, LV1.

(14) Luo, X.-S.; Ding, J.; Xu, B.; Wang, Y.-J.; Li, H.-B.; Yu, S.: Incorporating bioaccessibility into human health risk assessments of heavy metals in urban park soils. Science of The Total Environment 2012, 424, 88-96.

(15) Wilson, J.; Dixon, S.; Galke, W.; McLaine, P.: An investigation of dust lead sampling locations and children's blood lead levels. J Expos Sci Environ Epidemiol 2006, 17, 2-12.

(16) Watts, M. J.; O'Reilly, J.; Maricelli, A.; Coleman, A.; Ander, E. L.; Ward, N. I.: A snapshot of environmental iodine and selenium in La Pampa and San Juan provinces of Argentina. Journal of Geochemical Exploration 2010, 107, 87-93.

(17) Anand, T.; Rahi, M.; Sharma, P.; Ingle, G. K.: Issues in prevention of iron deficiency anemia in India. Nutrition 2014, 30, 764-770.

(18) Siyame, E. W. P.; Hurst, R.; Wawer, A. A.; Young, S. D.; Broadley, M. R.; Chilimba, A. D. C.; Ander, L. E.; Watts, M. J.; Chilima, B.; Gondwe, J.; Kang'ombe, D.; Kalimbira, A.; FairweatherTait, S. J.; Bailey, K. B.; Gibson, R. S.: A High Prevalence of Zinc- but not Iron-Deficiency among Women in Rural Malawi: a Cross-Sectional Study. International Journal for Vitamin and Nutrition Research 2013, 83, 176-187.

(19) Broadley, M. R.; White, P. J.: Eats roots and leaves. Can edible horticultural crops address dietary calcium, magnesium and potassium deficiencies? Proceedings of the Nutrition Society 2010, 69, 601-612.

(20) Vuckovic, N.; Ritenbaugh, C.; Taren, D. L.; Tobar, M.: A Qualitative Study of Participants' Experiences with Dietary Assessment. Journal of the American Dietetic Association 2000, 100, 1023-1028.

(21) Van Campen, D. R.; Glahn, R. P.: Micronutrient bioavailability techniques: Accuracy, problems and limitations. Field Crops Research 1999, 60, 93-113.

(22) Ikenaka, Y.; Nakayama, S.; Muzandu, K.; Choongo, K.; Teraoka, H.; Mizuno, N.; Ishizuka, M.: Heavy metal contamination of soil and sediment in Zambia. African Journal of Environmental Science and Technology 2010, 4.

(23) Kříbek, B.; Majer, V.; Veselovský, F.; Nyambe, I.: Discrimination of lithogenic and anthropogenic sources of metals and sulphur in soils of the central-northern part of the Zambian Copperbelt Mining District: A topsoil vs. subsurface soil concept. Journal of Geochemical Exploration 2010, 104, 69-86. 
Ndilila, W.; Callan, A. C.; McGregor, L. A.; Kalin, R. M.; Hinwood, A. L.: Environmental and toenail metals concentrations in copper mining and non mining communities in Zambia. International Journal of Hygiene and Environmental Health 2014, 217, 62-69.

(25) Slotnick, M. J.; Nriagu, J. O.: Validity of human nails as a biomarker of arsenic and selenium exposure: A review. Environmental Research 2006, 102, 125-139.

(26) Momoh, A.; Davies, T.; Akinsola, H.; Akinyemi, S. A.; Mhlongo, S.; Gitari, W.; Pindihama, G. K.: Human bioaccessibility of $\mathrm{Fe}, \mathrm{Mn}, \mathrm{Zn}$ and $\mathrm{Cu}$ from consumed earth materials in Vhembe District, South Africa. Transactions of the Royal Society of South Africa 2013, 68, 33-39.

(27) Ettler, V.; Vítková, M.; Mihaljevič, M.; Šebek, O.; Klementová, M.; Veselovský, F.; Vybíral, P.; Kř́ibek, B.: Dust from Zambian smelters: mineralogy and contaminant bioaccessibility. Environ Geochem Health 2014, 36, 919-933.

(28) Ettler, V.; Kř́bek, B.; Majer, V.; Knésl, I.; Mihaljevič, M.: Differences in the bioaccessibility of metals/metalloids in soils from mining and smelting areas (Copperbelt, Zambia). Journal of Geochemical Exploration 2012, 113, 68-75.

(29) BARGE: UBM procedure for the measurement of inorganic contaminant bioaccessibility from solid matrices. 2010; Vol. 2015.

(30) May, T. W.; Wiedmeyer, R. H. "A Table of Polyatomic Interferences in ICP-MS," U.S. Geological Survey, 1998.

(31) Denys, S.; Caboche, J.; Tack, K.; Rychen, G.; Wragg, J.; Cave, M.; Jondreville, C.; Feidt, C.: In Vivo Validation of the Unified BARGE Method to Assess the Bioaccessibility of Arsenic, Antimony, Cadmium, and Lead in Soils. Environmental Science \& Technology 2012, 46, 6252-6260.

(32) Watts, M. J.; Button, M.; Brewer, T. S.; Jenkin, G. R. T.; Harrington, C. F.: Quantitative arsenic speciation in two species of earthworms from a former mine site. Journal of Environmental Monitoring 2008, 10, 753-759.

(33) Ellickson, K. M.; Meeker, R. J.; Gallo, M. A.; Buckley, B. T.; Lioy, P. J.: Oral bioavailability of lead and arsenic from a NIST standard reference soil material. Archives of Environmental Contamination and Toxicology 2001, 40, 128-135.

(34) Oomen, A. G.; Brandon, E. F. A.; Swartjes, F. A.; Sips, A. J. A. M. "How can information on oral bioavailability improve human health risk assessment for lead-contaminated soils? Implementation and scientific basis," 2006.

(35) Wragg, J.; Cave, M.; Basta, N.; Brandon, E.; Casteel, S.; Denys, S.; Gron, C.; Oomen, A.; Reimer, K.; Tack, K.; Van de Wiele, T.: An inter-laboratory trial of the unified BARGE bioaccessibility method for arsenic, cadmium and lead in soil. Science of The Total Environment 2011, 409, 4016-4030. 
(36) Boisa, N.; Bird, G.; Brewer, P. A.; Dean, J. R.; Entwistle, J. A.; Kemp, S. J.; Macklin, M. G.: Potentially harmful elements (PHEs) in scalp hair, soil and metallurgical wastes in Mitrovica, Kosovo: The role of oral bioaccessibility and mineralogy in human PHE exposure. Environment International 2013, 60, 56-70.

(37) "Soil Generic Assessment Criteria for Human Health Risk Assessment," Contaminated Land Applications in Real Environments, 2010.

(38) Jayawardene, I.; Saper, R.; Lupoli, N.; Sehgal, A.; Wright, R. O.; Amarasiriwardena, C.: Determination of in vitro bioaccessibility of $\mathrm{Pb}, \mathrm{As}, \mathrm{Cd}$ and $\mathrm{Hg}$ in selected traditional Indian medicines. Journal of Analytical Atomic Spectrometry 2010, 25, 1275-1282.

(39) Sapsford, D. J.; Bowell, R. J.; Geroni, J. N.; Penman, K. M.; Dey, M.: Factors influencing the release rate of uranium, thorium, yttrium and rare earth elements from a low grade ore. Minerals Engineering 2012, 39, 165-172.

(40) Höllriegl, V.; Li, W. B.; Leopold, K.; Gerstmann, U.; Oeh, U.: Solubility of uranium and thorium from a healing earth in synthetic gut fluids: A case study for use in dose assessments. Science of The Total Environment 2010, 408, 5794-5800.

(41) Kaur, K.; Gupta, R.; Saraf, S. A.; Saraf, S. K.: Zinc: The Metal of Life. Comprehensive Reviews in Food Science and Food Safety 2014, 13, 358-376.

(42) Dhalleine, C.; Assifaoui, A.; Moulari, B.; Pellequer, Y.; Cayot, P.; Lamprecht, A.; Chambin, O.: Zinc-pectinate beads as an in vivo self-assembling system for pulsatile drug delivery. International Journal of Pharmaceutics 2011, 414, 28-34.

(43) Ternay, A. L.: Sidney A. Katz and Harry Salem. The Biological and Environmental Chemistry of Chromium. VCH Publishers, New York, 1994. Journal of Applied Toxicology 1995, 15, 337-337.

(44) Chatzistathis, T.; Alifragis, D.; Papaioannou, A.: The influence of liming on soil chemical properties and on the alleviation of manganese and copper toxicity in Juglans regia, Robinia pseudoacacia, Eucalyptus sp. and Populus sp. plantations. Journal of Environmental Management 2015, 150, 149-156.

(45) Jardine, P. M.; Stewart, M. A.; Barnett, M. O.; Basta, N. T.; Brooks, S. C.; Fendorf, S.; Mehlhorn, T. L.: Influence of Soil Geochemical and Physical Properties on Chromium(VI) Sorption and Bioaccessibility. Environmental Science \& Technology 2013, 47, 11241-11248.

(46) Wang, D.; Wang, C.; Wei, Z.; Qi, H.; Zhao, G.: Effect of rare earth elements on peroxidase activity in tea shoots. Journal of the Science of Food and Agriculture 2003, 83, 1109-1113. 
(47) Xinde, C.; Xiaorong, W.; Guiwen, Z.: Assessment of the bioavailability of rare earth

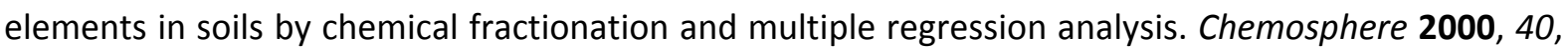
23-28.

(48) Li, X.; Chen, Z.; Chen, Z.; Zhang, Y.: A human health risk assessment of rare earth elements in soil and vegetables from a mining area in Fujian Province, Southeast China. Chemosphere 2013, 93, 1240-1246.

(49) Xu, X.; Zhu, W.; Wang, Z.; Witkamp, G. J.: Distribution of rare earths and heavy metals in field-grown maize after application of rare earth-containing fertilizers. Science of The Total Environment 2002, 293, 97-105.

(50) Evans, C. H.: Interesting and useful biochemical properties of lanthanides. Trends in Biochemical Science 1983, 445-449.

(51) Zhu, W.; Xu, S.; Shao, P.; Zhang, H.; Wu, D.; Yang, W.; Feng, J.; Feng, L.: Investigation on liver function among population in high background of rare earth area in South China. Biological Trace Element Research 2004, 104. 
Table 1: Mean STOM phase bioaccessible concentrations $\left(\mathrm{mg} \mathrm{kg}^{-1}\right)$, standard deviation and percentage relative standard deviation for uncertified elements. " $\checkmark$ " denotes elements with $\leq 10 \%$ RSD, " " 10-20\% RSD, " $x$ " > 20\% RSD. "<DL" denotes elements with concentrations below instrument detection limit.

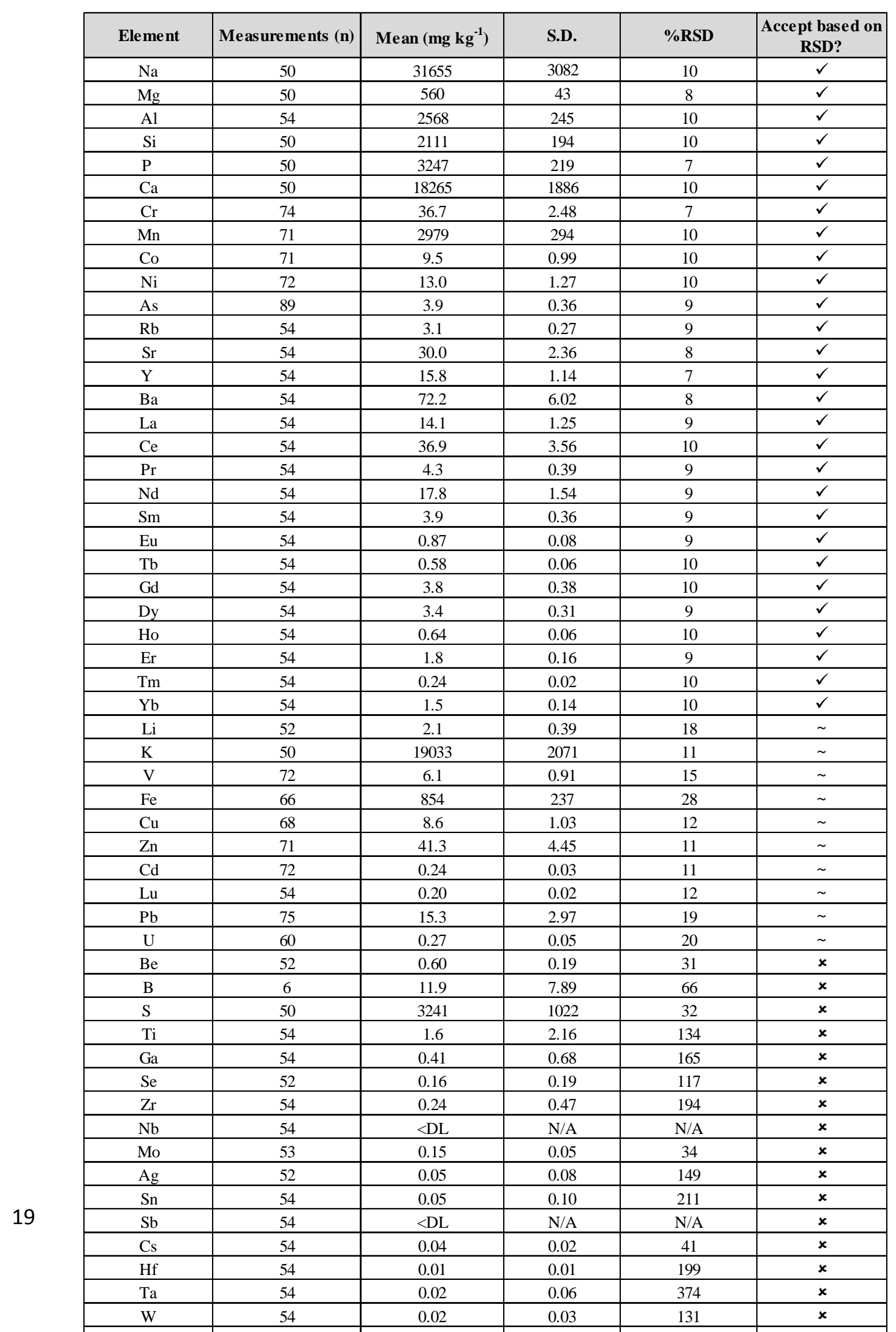


Table 2: Mean STOM+INT phase bioaccessible concentrations $\left(\mathrm{mg} \mathrm{kg}^{-1}\right)$, standard deviation and percentage relative standard deviation for uncertified elements. " $\checkmark$ " denotes elements with $\leq 10 \%$ RSD, “ " 10-20\% RSD, " $x$ " >20\% RSD. "<DL" denotes elements with concentrations below instrument detection limit.

\begin{tabular}{|c|c|c|c|c|c|}
\hline Element & Measurements (n) & Mean (mg kg $\left.{ }^{-1}\right)$ & S.D. & \%RSD & $\begin{array}{c}\text { Accept based on } \\
\text { RSD? }\end{array}$ \\
\hline $\mathrm{Na}$ & 44 & 270025 & 13868 & 5 & $\checkmark$ \\
\hline $\mathrm{Mg}$ & 42 & 829 & 58 & 7 & $\checkmark$ \\
\hline $\mathrm{K}$ & 44 & 36371 & 2028 & 6 & $\checkmark$ \\
\hline $\mathrm{Rb}$ & 48 & 4.2 & 0.44 & 10 & $\checkmark$ \\
\hline $\mathrm{P}$ & 44 & 3020 & 505 & 17 & $\sim$ \\
\hline $\mathrm{Ca}$ & 44 & 19683 & 2088 & 11 & $\sim$ \\
\hline $\mathrm{V}$ & 55 & 3.4 & 0.49 & 14 & $\sim$ \\
\hline $\mathrm{Cr}$ & 51 & 13.1 & 2.41 & 18 & $\sim$ \\
\hline $\mathrm{Mn}$ & 62 & 1810 & 325 & 18 & $\sim$ \\
\hline Co & 69 & 5.5 & 0.71 & 13 & $\sim$ \\
\hline $\mathrm{Ni}$ & 65 & 10.5 & 1.10 & 11 & $\sim$ \\
\hline As & 77 & 3.3 & 0.41 & 12 & $\sim$ \\
\hline $\mathrm{Sr}$ & 48 & 24.5 & 3.32 & 14 & $\sim$ \\
\hline $\mathrm{Li}$ & 46 & 2.0 & 1.05 & 53 & $x$ \\
\hline $\mathrm{Be}$ & 46 & 0.17 & 0.14 & 78 & $x$ \\
\hline $\mathrm{B}$ & 6 & 22.3 & 35.6 & 160 & $x$ \\
\hline $\mathrm{Al}$ & 48 & 925 & 319 & 34 & $x$ \\
\hline $\mathrm{Si}$ & 44 & 2408 & 477 & 20 & $x$ \\
\hline $\mathrm{S}$ & 44 & 7585 & 2381 & 31 & $x$ \\
\hline $\mathrm{Ti}$ & 47 & 1.6 & 1.89 & 119 & $x$ \\
\hline $\mathrm{Fe}$ & 50 & 342 & 101 & 29 & $x$ \\
\hline $\mathrm{Cu}$ & 59 & 8.7 & 1.88 & 22 & $x$ \\
\hline $\mathrm{Zn}$ & 57 & 9.5 & 2.35 & 25 & $x$ \\
\hline $\mathrm{Ga}$ & 48 & 0.07 & 0.13 & 181 & $x$ \\
\hline Se & 46 & 0.27 & 0.276 & 102 & $x$ \\
\hline $\mathrm{Y}$ & 44 & 5.0 & 1.42 & 28 & $x$ \\
\hline $\mathrm{Zr}$ & 48 & $<\mathrm{DL}$ & N/A & N/A & $x$ \\
\hline $\mathrm{Nb}$ & 48 & $<\mathrm{DL}$ & N/A & N/A & $x$ \\
\hline Mo & 47 & 1.5 & 0.33 & 22 & $x$ \\
\hline $\mathrm{Ag}$ & 47 & $<\mathrm{DL}$ & N/A & N/A & $x$ \\
\hline $\mathrm{Cd}$ & 57 & 0.11 & 0.03 & 26 & $x$ \\
\hline $\mathrm{Sn}$ & 48 & 0.03 & 0.35 & 1288 & $x$ \\
\hline $\mathrm{Sb}$ & 49 & $<\mathrm{DL}$ & N/A & N/A & $x$ \\
\hline Cs & 47 & 0.06 & 0.05 & 91 & $x$ \\
\hline $\mathrm{Ba}$ & 48 & 22.5 & 7.23 & 32 & $x$ \\
\hline $\mathrm{La}$ & 47 & 4.2 & 1.34 & 32 & $x$ \\
\hline $\mathrm{Ce}$ & 47 & 11.4 & 3.78 & 33 & $x$ \\
\hline $\mathrm{Pr}$ & 48 & 1.3 & 0.47 & 36 & $x$ \\
\hline $\mathrm{Nd}$ & 48 & 5.4 & 1.96 & 36 & $x$ \\
\hline $\mathrm{Sm}$ & 48 & 1.2 & 0.45 & 38 & $x$ \\
\hline $\mathrm{Eu}$ & 48 & 0.26 & 0.10 & 38 & $x$ \\
\hline $\mathrm{Tb}$ & 48 & 0.18 & 0.07 & 38 & $x$ \\
\hline $\mathrm{Gd}$ & 48 & 1.1 & 0.43 & 38 & $x$ \\
\hline Dy & 48 & 1.1 & 0.40 & 38 & $x$ \\
\hline Ho & 48 & 0.20 & 0.07 & 36 & $x$ \\
\hline Er & 48 & 0.58 & 0.20 & 36 & $x$ \\
\hline $\mathrm{Tm}$ & 48 & 0.08 & 0.03 & 36 & $x$ \\
\hline $\mathrm{Yb}$ & 48 & 0.53 & 0.19 & 35 & $x$ \\
\hline $\mathrm{Lu}$ & 48 & 0.08 & 0.03 & 39 & $x$ \\
\hline $\mathrm{Hf}$ & 48 & $<\mathrm{DL}$ & N/A & N/A & $x$ \\
\hline $\mathrm{Ta}$ & 48 & 0.01 & 0.14 & 1980 & $x$ \\
\hline W & 48 & 0.32 & 0.48 & 152 & $x$ \\
\hline $\mathrm{Tl}$ & 48 & 0.04 & 0.07 & 192 & $x$ \\
\hline $\mathrm{Pb}$ & 56 & 1.9 & 0.44 & 23 & $x$ \\
\hline $\mathrm{Bi}$ & 48 & 0.01 & 0.01 & 249 & $x$ \\
\hline Th & 43 & 0.23 & 0.08 & 35 & $x$ \\
\hline $\mathrm{U}$ & 51 & 0.20 & 0.06 & 28 & $x$ \\
\hline
\end{tabular}


Table 3: Mean bioaccessibility fractions (\%BAF), standard deviation and percentage relative standard deviation for uncertified elements. Highlight denotes $\leq 10 \%$ RSD.

\begin{tabular}{|c|c|c|c|}
\hline Element & Mean (\%BAF) & SD & \%RSD \\
\hline $\mathrm{Li}$ & 5.1 & 0.97 & 19 \\
\hline $\mathrm{Be}$ & 22.7 & 9.0 & 39 \\
\hline $\mathrm{Na}$ & 17484 & 9223 & 53 \\
\hline $\mathrm{Mg}$ & 25.4 & 18.0 & 71 \\
\hline $\mathrm{Al}$ & 6.7 & 0.66 & 10 \\
\hline $\mathrm{P}$ & 117 & 9.0 & 8 \\
\hline $\mathrm{S}$ & 609 & 313 & 51 \\
\hline $\mathrm{K}$ & 329 & 61.2 & 19 \\
\hline $\mathrm{Ca}$ & 95 & 11.6 & 12 \\
\hline $\mathrm{Ti}$ & 0.16 & 0.15 & 98 \\
\hline $\mathrm{V}$ & 1.8 & 0.31 & 17 \\
\hline $\mathrm{Cr}$ & 16.6 & 2.6 & 16 \\
\hline $\mathrm{Mn}$ & 41.0 & 6.4 & 16 \\
\hline $\mathrm{Fe}$ & 0.53 & 0.20 & 38 \\
\hline Co & 21.0 & 3.9 & 19 \\
\hline $\mathrm{Ni}$ & 15.5 & 1.8 & 12 \\
\hline $\mathrm{Cu}$ & 33.4 & 5.8 & 17 \\
\hline $\mathrm{Zn}$ & 22.3 & 3.7 & 17 \\
\hline $\mathrm{Ga}$ & 7.6 & 13.8 & 183 \\
\hline As & 4.5 & 0.50 & 11 \\
\hline Se & 57.6 & 55.7 & 97 \\
\hline $\mathrm{Rb}$ & 7.1 & 1.2 & 17 \\
\hline $\mathrm{Sr}$ & 43.1 & 2.7 & 6 \\
\hline $\mathrm{Y}$ & 46.3 & 4.3 & 9 \\
\hline $\mathrm{Zr}$ & 0.56 & 0.54 & 97 \\
\hline $\mathrm{Nb}$ & 0.30 & 0.26 & 86 \\
\hline Mo & 17.8 & 7.7 & 43 \\
\hline $\mathrm{Ag}$ & 133 & 238 & 180 \\
\hline $\mathrm{Cd}$ & 60.3 & 9.9 & 16 \\
\hline Sn & 2.6 & 2.4 & 92 \\
\hline $\mathrm{Sb}$ & 6.0 & 7.2 & 121 \\
\hline Cs & 1.5 & 0.37 & 25 \\
\hline $\mathrm{Ba}$ & 25.9 & 2.2 & 9 \\
\hline $\mathrm{La}$ & 36.8 & 5.4 & 15 \\
\hline $\mathrm{Ce}$ & 34.6 & 8.6 & 25 \\
\hline $\mathrm{Pr}$ & 37.3 & 4.0 & 11 \\
\hline $\mathrm{Nd}$ & 36.2 & 8.9 & 25 \\
\hline $\mathrm{Sm}$ & 37.5 & 4.1 & 11 \\
\hline $\mathrm{Eu}$ & 39.9 & 4.9 & 12 \\
\hline $\mathrm{Tb}$ & 42.1 & 4.4 & 10 \\
\hline $\mathrm{Gd}$ & 41.7 & 4.2 & 10 \\
\hline Dy & 40.4 & 3.5 & 9 \\
\hline Ho & 41.6 & 4.1 & 10 \\
\hline $\mathrm{Er}$ & 40.1 & 3.8 & 9 \\
\hline $\mathrm{Tm}$ & 36.8 & 3.6 & 10 \\
\hline $\mathrm{Yb}$ & 35.3 & 3.6 & 10 \\
\hline $\mathrm{Lu}$ & 35.1 & 5.0 & 14 \\
\hline Hf & 0.77 & 0.95 & 124 \\
\hline $\mathrm{Ta}$ & 16.1 & 27.9 & 173 \\
\hline $\mathrm{W}$ & 27.2 & 28.0 & 103 \\
\hline $\mathrm{Tl}$ & 14.6 & 9.0 & 62 \\
\hline $\mathrm{Pb}$ & 17.6 & 5.6 & 32 \\
\hline $\mathrm{Bi}$ & 1.7 & 0.87 & 52 \\
\hline Th & 1.3 & 0.93 & 74 \\
\hline $\mathrm{U}$ & 12.8 & 2.2 & 17 \\
\hline
\end{tabular}

